This article has been accepted for publication in Applied Linguistics Published by Oxford University Press.

https://doi.org/10.1093/applin/amab072

The Impact of Race on Speech Perception and Accentedness Judgments in Racially Diverse and Non-Diverse Groups

\author{
Ethan Kutlu ${ }^{1,2,3}$, Mehrgol Tiv ${ }^{4}$, Stefanie Wulff ${ }^{5,6}$, and Debra Titone ${ }^{4}$ \\ ${ }^{1}$ Department of Linguistics, University of Iowa \\ ${ }^{2}$ Department of Psychological and Brain Sciences, University of Iowa \\ ${ }^{3}$ DeLTA Center, University of Iowa \\ ${ }^{4}$ Department of Psychology, McGill University \\ ${ }^{5}$ Department of Linguistics, University of Florida \\ ${ }^{6}$ Department of Language and Culture, UiT The Arctic University of Norway
}

Address correspondence to:

Dr. Ethan Kutlu

Department of Linguistics, University of Iowa

Iowa City, Iowa, 52242, USA

E-mail: ethankutlu@gmail.com

Web link for this project: https://osf.io/h86c4/?view_only=1f4f67e58fb245d59c1649b9cafdfcde 


\begin{abstract}
Standard varieties are often perceived as morally superior compared to nonstandard varieties (Hill 2008). Consequently, these differences lead to ideologies that racialize nonstandard varieties (Rosa 2016), and increase the negative stereotypes towards nonstandard varieties (Giles \& Watson 2013). One outlet of such stereotypes can be observed with speech intelligibility and accentedness judgments. This study examines whether seeing a white or a South Asian face impacts listeners' perception of American, British, Indian English and to what extent listeners' social network diversity plays a role in predicting their perception of speech. Results indicated that intelligibility scores decreased and accentedness judgments increased for all varieties when speech was paired with South Asian faces. However, listeners with less racially diverse social networks had the highest accentedness judgments. Understanding how to account for the emergence and behavioral implications of different English varieties is a pressing question, and these results shed light on how English varieties are perceived. The implications will be discussed in light of language teaching, linguistic practices, and language research.
\end{abstract}

Keywords: audio-visual speech perception, raciolinguistics, English varieties, accentedness judgments, race, NNEST 


\section{The Impact of Race on Speech Perception and Accentedness Judgments in Racially Diverse and Non-Diverse Groups}

English holds an essential role in global communication. In today's world, the majority of English speakers are not Western nor white but mostly belong to minority and multilingual communities. However, Western and white-dominant English practices are still associated with the standard variety (Kubota 2020), while English varieties spoken by minorities, multilingual communities, or BIPOC (Black, Indigenous, People of Color) populations, hence the majority, are labeled as nonstandard varieties. Some of these varieties are also often associated with foreign accents (Babel \& Russell 2015; Kachru 1986; Kutlu 2020; Shuck 2006). The goal of this study is to measure attitudes towards different varieties of English and examine how racial otherness is cultivated in different social networks and to fill the gap in how racialized bodies are discursively constructed in relation to language in speech perception, particularly in accentedness judgments (Sekimoto 2018; Oostendorp 2021), and the implications of such racialization in the workplace for English speaking communities.

From well-established research on language attitudes, it is known that speakers of nonstandard varieties face linguistic and social discrimination (Derwing 2003; Giles \& Watson 2013; Hill 2008; Kircher \& Fox 2019) as standard varieties, which serve a utilitarian value (Gardner \& Lambert 1972), are regarded as correct language use. With this utilitarian value comes high status, offering (socio-)economic and individualistic power.

Although both regional and foreign accents are thought to deviate from the standard variety, and stigmatization towards these varieties is prevalent, many argue that regional accents are closer in distance to the standard variety, while foreign accents are thought to be further away from it (see Perceptual Distance Hypothesis: Floccia et al. 2006). Moreover, speakers of 
regional varieties are granted native speaker status. This status is not granted to those who speak a foreign variety of English, despite it being the case that these speakers often grow up hearing and using their own variety of English from birth or from an early age (Maxwell et al. 2021).

According to Kachru (1986), Indian English (among other varieties, such as Nigerian English) is considered an outer circle English variety. Speakers of outer circle English varieties, despite speaking English as (one of) their first language(s) or being fluent in English, are perceived as non-legitimized speakers of English and are not perceived as native speakers (Higgins 2003; Kutlu 2020; Oostendorp 2021). On the contrary, speakers of inner circle varieties (e.g., American English, Australian English, British English, Canadian English, etc.) are automatically granted this native speaker status. What differentiates inner and outer circle varieties stems from their divergent colonial past. While English either originated in or spread to inner circle varieties through settler colonialism (i.e., Europeans settling in different countries), it spread to outer circle varieties through imperial expansion and the pursuit of exploitative colonialism. This colonial history embargoes who gets the native speaker status in the Englishspeaking communities, even in cases where English is identified as one of the official languages (e.g., Indian English, see Schneider 2007).

In addition, outer circle varieties are spoken predominantly by non-white speakers, something which has not been discussed nor compared extensively in previous literature. From a large body of research on race and language, it is known that language is racialized and that language spoken by minorities is often subjected to marginalization and that accents play a crucial role in shaping subjectivities towards the racialization of these languages (Soudien \& Botsis 2011). Linguistic performance of these racialized bodies is always criticized for its legitimacy as they are not seen as the ideal speakers of English (i.e., the colonizer language) 
(Rosa 2016). For instance, Oostendorp (2021) showed that Black students who are high proficient users of Afrikaans were deemed to be exceptional or their language practices were questioned as being "suspiciously" good. Such results suggest that it is often not the case of proficiency in language that causes scrutiny of linguistic competence, but rather which bodies produce the language.

It is evident that every human has their own authentic accent, but accents have been used to other speakers through unrealistic expectations, as is particularly the case for multilingual and BIPOC communities (Lippi-Green 1994; Subtirelu 2015; Subtirelu et al. 2019). The maintenance of this ideal native speakerism often overlaps with bodily aesthetics, such as skin color, and these aesthetics are stereotypically perceived as who gets to be the native speaker of the language (Cowie 2007; Ramjattan 2019a; Shuck 2006). Such ideologies create unequitable work environments for those who speak different varieties of Englishes or are English speaking bilinguals (Subtirelu 2017). For instance, Indian English speakers who worked in call centers were asked to perform with a neutral accent ${ }^{1}$ (Cowie 2007). Makoe and McKinney (2014) showed that white teachers were perceived as unaccented or normal in South African schools. In fact, whiteness is often attested to being the prototypical look for a typical native English speaker (Ramjattan 2019). In an extensive mixed method study, Subtirelu (2015) analyzed instructor ratings along with comments on the RateMyProfessor.com website ${ }^{2}$. His findings showed that instructors who had last names typically associated with so-called native speakers of the US

\footnotetext{
${ }^{1}$ Cowie (2007) argues that neutral was interpreted differently depending on the context. For instance, older English Language Teachers (ELTs) promoted more positive attitudes towards British English while younger ELTs had more positive attitudes towards American English suggesting that their norms for neutrality are governed by two inner circle varieties.

${ }^{2}$ RateMyProfessor.com is a website in which instructors receive ratings and comments regarding their teaching performance.
} 
were found to be clearer and more helpful compared to instructors who had last names of Chinese or Korean origins.

Another example of how race is applied in language practices is often seen in the discussion of non-native ${ }^{3}$ English-speaking teachers (NNEST) where nativeness is often linked to accent-free forms of speech (Anya et al. 2010; Higgins 2003; Holliday \& Aboshiha 2009; Ramjattan 2019). Although accents do not redeem intelligibility of speech (Munro \& Derwing 1995), the pursuit of accent-free speech in teaching has remained as an unrealistic ideology that discriminates against non-white, non-Western speakers of English.

This unrealistic ideological search has been reflected in many English Language Teaching (ELT) job posts, where many platforms list a requirement of "native speaker of English", a term that further perpetuates discrimination and is also mixed with other discriminatory features such as race (Dewaele 2018; Dewaele et al. 2020; Adrian Holliday \& Aboshiha 2009; Kutlu 2020; Mahboob 2018; Mahboob \& Golden 2013).

Therefore, race not only plays a crucial role in forming language attitudes, but it also informs language practices and policies, it holds its hegemonic presence (Sekimoto 2018; Ortega 2021) in our everyday life. This needs to be discussed extensively in language research (Holliday \& Aboshiha 2009; Kubota 2020).

One area of research that can successfully document the reflection of racialized bodies in native speakerism, and perception of language practices is audio-visual speech perception in different English varieties, where seeing race (i.e., viewing a non-white face versus a white face)

\footnotetext{
${ }^{3}$ The terms native and non-native are only used to allude to the previous research throughout this paper. The authors follow guidance proposed by Dewaele (2018) and Dewaele et al. (2020) to avoid such terminology which is considered to perpetuate more discrimination in language research. These terms are in italics throughout the text.
} 
holds the symbolic meaning of whether the person can be attested to having a foreign accent or not, hence leading to differential speech perception. Munro and Derwing's groundbreaking research (Derwing \& Munro 1997; Munro \& Derwing 1995) established the cornerstones of speech perception research: intelligibility, comprehensibility, and accentedness ${ }^{4}$. Ample work on audio-visual speech perception ${ }^{5}$ has shown that visual information impacts how listeners engage with other interlocutors (e.g., Babel \& Russell 2015; Kutlu 2020; McGowan 2015; Yi et al. 2013, 2014; Zheng \& Samuel 2017). Therefore, visual information ${ }^{6}$ has often been investigated through the lens of social categorization in speech perception, as both associating a visual cue or an accent/variety with a particular race/ethnicity leads to social categorization (e.g., work on matched-guise technique (Campbell-Kibler 2011; Kircher 2016; Lambert et al. 1960; Paladino \& Mazzurega 2019). Such categorization can be evaluated differently depending on listeners' background and who or what they are categorizing (Dragojevic et al. 2018). For instance, Niedzielski (1999) reported that listeners' perception of vowels could be altered depending on who they believed they were listening to.

Rubin (1992) demonstrated similar results in classroom dynamics. Undergraduate students were asked to listen to American English recordings, half of which were paired with Asian faces and the other half with white faces. When paired with Asian faces, comprehension ratings of American English were lower and the speech was considered more accented compared to the same dialect presented with white faces. Later, Kang and Rubin (2009) argued that

\footnotetext{
${ }^{4}$ Intelligibility is often measured by transcription accuracy and denotes to what extent listeners understand speaker's utterances. Comprehensibility is the level of difficulty in accessing the message produced by the speaker. Accentedness is the extent to which a speaker's speech is perceived closer or further away from a given variety. Note that while intelligibility and comprehensibility are shown to highly correlate with each other, accentedness judgments are often found to be weakly correlated with these measures (Munro and Derwing 1995).

${ }^{5}$ More broadly, yet outside the scope of this paper, the McGurk effect has shown that seeing certain facial movements leads to the illusion of perceived sounds.
} 
listeners use cues such as race, ethnicity, and nationality to attribute stereotypes to speakers via previously established attitudes.

Although extensively studied, audio-visual speech perception studies have not yet measured individual differences in life experiences that is observed in listeners' social network. Recent studies on social network analysis suggest that social network approaches can be used to identify language dynamics in a given social context, allowing researchers to quantify exposure differences. In a series of groundbreaking studies on linguistic structures and variability, Lev-Ari demonstrated that the number of people one interacts with (social network size) defines the rate at which linguistic changes happen in a given language/variety. Lev-Ari (2018) revealed that having a larger social network could increase differing phonological and semantic abilities (LevAri 2016), facilitate lexical prediction (Lev-Ari \& Shao 2017), and decrease malleable linguistic representation in production (Lev-Ari 2017). Importantly, work led by Tiv and colleagues provided evidence on how social networks are crucial particularly in the context of multilingual spaces (Tiv et al. 2020). The social network approach can identify relationships among language users and what language(s) are used among those users (Tiv et al., under review). The methodology of using social network is therefore crucial in understanding how attitudes towards different varieties are shaped, particularly in multilingual contexts (Tiv et al. 2020).

Importantly, the majority of this audio-visual work has also focused on perception of inner circle varieties (e.g., American, British, Canadian Englishes) or expanding circle varieties (i.e., LX speakers' (see footnote 3) English production (e.g., Chinese- or Korean-accented English)). While little is known regarding the perception of outer circle varieties, Kutlu (2020) compared two varieties of English that belong to inner and outer circles with distinct perceived prestige levels (i.e., American, Indian). They used previously normed recordings with high 
intelligibility. Results showed that listeners' accentedness judgments increased when they heard either American English or Indian English paired with a South Asian face compared to a white face. Importantly, there was no change when viewing a white face paired with the audio, but only when a South Asian face was shown. This suggests that the effects are not due to additional demands from seeing a face on the screen, but rather the social implications (i.e., biases) of viewing a South Asian face. These findings showed that some Englishes were perceived as more accented, not because of their intelligibility, but because of who spoke them (see Holliday (2006) and Holliday \& Aboshiha (2009) for an extensive discussion on this issue). Therefore, a more comprehensive analysis of inner and outer circle dynamics is needed to understand how listeners' exposure to racial diversity impact their speech perception of these different Englishes.

\section{The Present Study}

This study aims to expand previous work on audio-visual studies (Babel \& Russell 2015; McGowan 2015; Author 2020) to the perception of outer circle Englishes by examining accentedness judgments and intelligibility measures. This examination of outer circle Englishes is done by centralizing race in defining whose language practices are perceived more or less accented. Furthermore, this analysis is done in novel ways (i) by comparing three varieties, and (ii) by focusing on listeners' social network to better understand language dynamics in groups of individuals who have more or less diverse social networks. Therefore, intelligibility (i.e., transcription accuracy) and accentedness judgments were collected to assess whether listeners' ability to transcribe sentences and their subjective accentedness judgments of these varieties are impacted by the race of the faces. American, British, and Indian English were chosen as they reflect the different racialized ideologies (e.g., see Kutlu 2020; Kutlu and Wiltshire 2020; 
Maxwell et al. 2021) and represent a hierarchy of prestige through their historical evolution (i.e., codification and association with powerful groups; see Dragojevic (2020)).

If race impacts speech perception, then we expect lower intelligibility scores when we present the varieties with South Asian faces. If race does not impact speech perception, then we expect no difference in intelligibility when we present speech with white and/or South Asian faces. Consequently, due to the racialization of different language varieties, we expect Indian English to be judged as more accented compared to both American and British varieties. We also expect these predictions to be constrained by listeners' exposure to racial diversity through their personal social networks. We expect that listeners with less racial diversity in their social network will judge speech presented with South Asian faces as more accented and have lower intelligibility towards Indian English as well as South Asian faces.

\section{Methodology}

\section{Participants}

Fifty-eight participants (woman $n=39$, $\operatorname{man} n=19$ ) were tested. All participants were undergraduate students $\left(M_{\text {age }}=19.2\right.$ years old, $S D=1.2$ years old $)$. Eleven more participants were tested but were not included in the final analysis due to extensive exposure (more than 10 years of exposure) to Tamil, Telugu, Indian English, and British English (as indicated in their language background questionnaire). There were 6 Black, 9 Hispanic, 2 Southeast Asian, 1 Southeast Asian and white, 1 white and Asian, 1 white and Black, 8 white and Hispanic, and 30 white participants. All participants reported that their dominant language was American English. Depending on participants' answers to the social network questionnaire, those who reported having more than one tie with someone in their close network (i.e., someone that they interact 
with almost every day) who identifies with a racial or ethnic background outside of their own racial and ethnic background were grouped in the MoreDiverse category. Those with ties only to individuals within their own racial and ethnic background were grouped in the LessDiverse (LessDiverse $\mathrm{n}=24$, MoreDiverse $\mathrm{n}=34$ ).

\section{Auditory stimuli}

One hundred and twenty sentences from past studies (Bradlow \& Alexander 2007; Author 2020; McGowan 2015) were recorded (see OSF page). These sentences were extensively used in previous speech perception studies and were normed and controlled for their word frequency. For American English, the recordings of two female speakers were brought in from an online speech archive $e^{7}$. Six Indian English speakers were recorded on the testing campus. Indian English consists of many sub-varieties as India is one of the largest multilingual country in the world, housing over 120 mother tongues. To account for phonological differences that can be observed in Indian English, only Tamil and/or Telugu speakers who also speak Indian English were recorded. Tamil and Telugu were chosen as they are among the most widely spoken languages in India (Census of India 2011). All Indian English speakers self-identified their variety as standard Indian English and were all graduate students who arrived to the USA one semester prior to the recording session. For the British English recordings, 6 female speakers were recorded in Reading, UK. They were all born and raised in Reading, UK and self-identified their variety as Standard British English. All twelve speakers were paid $\$ 10$ for each recording session, and each session took less than 2 hours. Participants first practiced the sentences by

\footnotetext{
${ }^{7}$ The OSCAAR speech corpus (OSCAAR: The Online Speech/Corpora Archive and Analysis Resource, talker 439 and 441 (filenames: SC_S_ENF_29_EN, SC_S_ENF_18_EN).
} 
themselves and were then asked to read them out loud in a quiet room. Participants read every sentence twice to ensure that recordings were as natural as possible.

Sixteen judges (i.e., undergraduate students who attended the same college as the participants, with similar language backgrounds) evaluated the recordings from all speakers (see Supplementary Materials on OSF page). Based on the norming data, we picked six female speakers for the experiment (two female speakers for each variety). To make the task slightly challenging for the participants, and to assess whether noise impacts the intelligibility of different varieties of Englishes (Van Engen et al. 2014; Van Engen \& Bradlow 2007), we added $4 \mathrm{~dB}$ (signal to noise ratio) white noise to our recordings. This way, we also ensured that the task mimicked real-world scenarios where there is often background noise during speech perception and that participants paid more attention (i.e., listened to them carefully) to each stimulus. This was chosen based on previous studies (McGowan 2015) and also from the norming study.

\section{Visual stimuli}

For visual stimuli, we used two previously normed and controlled face databases. South Asian faces were taken from the KKWETC face database (Satone 2017). White faces were taken from the Chicago face database (Ma et al. 2015). Both of these face databases have been used extensively in vision research. From each database, we picked three female faces that were shown to display no emotional valence (see Appendix A). Six white and South Asian faces (3:3 ratio) were matched with three different varieties by way of a fully randomized Latin-square counterbalance distribution (e.g., one white face with American English speaker 1, one white face with British English speaker 1, one white face with Indian English speaker 1, etc.). This yielded four lists for the intelligibility experiment. Each speaker was paired with one face per list and each participant only saw one list ( $n=120$ sentences). For the accentedness judgments, 
participants heard half of the 120 sentences to eliminate any adaptation to speakers' accent which was shown to impact speech perception (Xie et al. 2017). Further examination of the list as a variable did not yield any significant differences suggesting that neither speaker 1 nor 2 in either variety (i.e., American, British, Indian) changed listeners' accentedness judgments which conforms with the norming data (see Table 5 in Supplementary Materials on OSF).

\section{Procedure}

Participants completed a language background questionnaire (Li et al. 2020), the LexTale English proficiency task (Lemhöfer \& Broersma 2012), and the revised version of Lev-Ari's (2017) social network questionnaire (see OSF page). They then completed the experimental tasks, namely the intelligibility task followed by the accentedness judgment task. All testing was completed in a quiet room. The experiment took 1.5 hours to complete, and participants received 3 class credits upon completion of the experiment.

The accentedness judgment and the intelligibility tasks were administered via PsychoPy (Peirce 2017). First, an image was shown on the computer screen for $250 \mathrm{~ms}$. Then, the auditory stimulus played. The PsychoPy script was written in such a way that participants were not allowed to start typing nor judge the sentences in either experiment before the stimulus played fully. Participants were instructed regarding this information and completed a practice trial with the research assistant that consisted of three sentences which were excluded from the analysis.

For the intelligibility task, participants were instructed to look at a speaker's face on the screen, listen to the speech in noise carefully, and type the sentences as accurately as possible. To facilitate typing, participants were advised to avoid punctuation or capital letters (Figure 1). For the accentedness judgments task, participants were again asked to listen to the sentences and were then asked to judge (9-point scale) whether the speaker had an accent or not by using the 
number buttons on the keyboard. Participants' responses were recorded. (Figure 2 and see Table 1 for descriptive results).
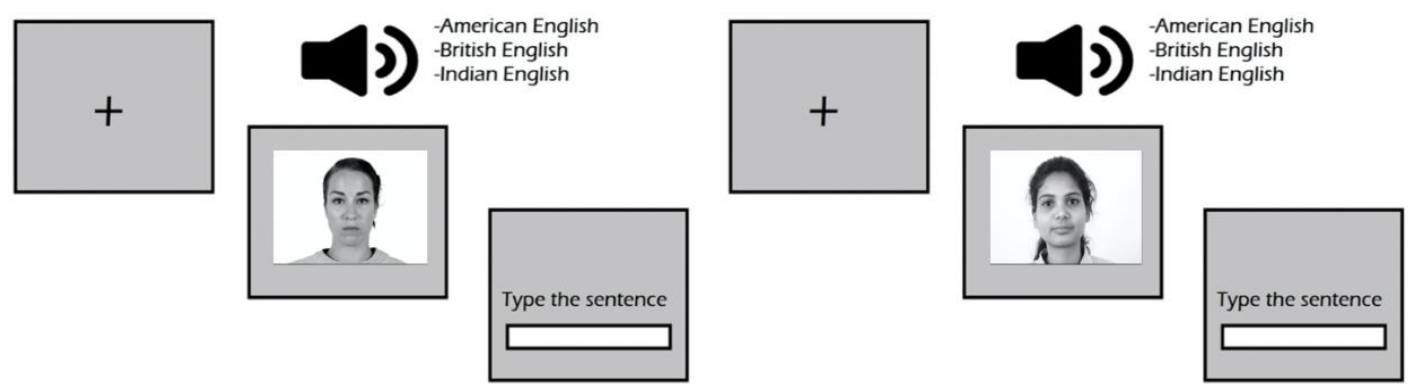

Figure 1. The design of the intelligibility task with a representative white face on the left and a representative South Asian face on the right. Both pictures are allowed to be used for publication purposes.
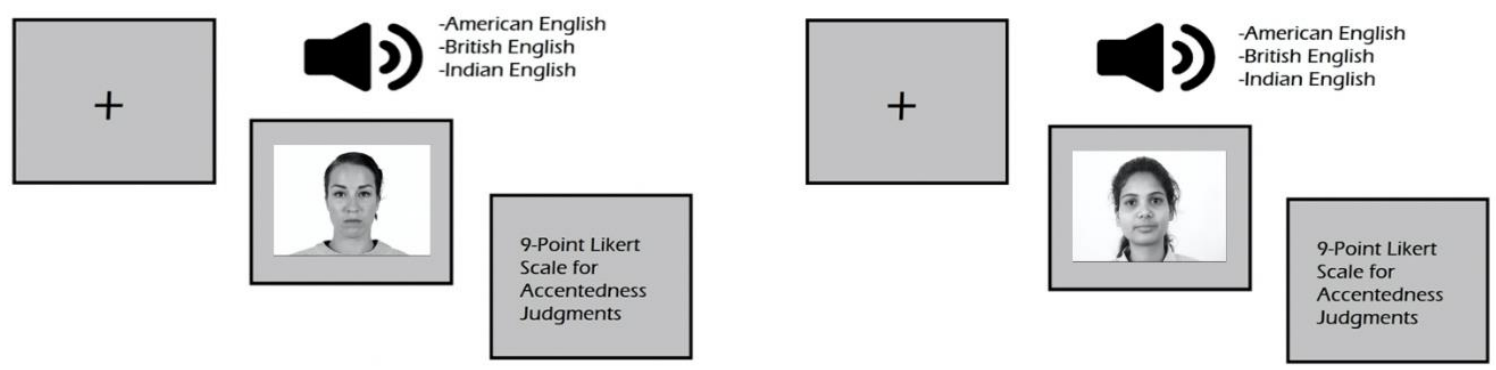

Figure 2. The design of the accentedness task with a white face on the left and a South Asian face on the right.

Table 1. Summaries of the Mean (M) and Standard Deviation (SD) of the accentedness judgments and intelligibility scores for both racially diverse and not diverse groups.

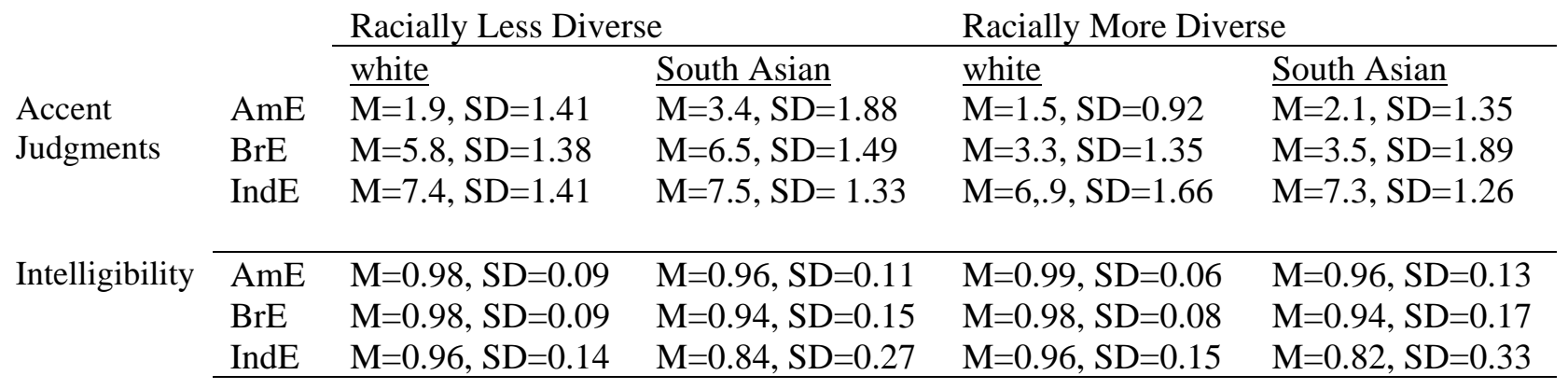




\section{Results}

\section{Intelligibility Scores}

Intelligibility scores were calculated through transcription accuracy. For each sentence, content words were selected and their transcription accuracy was calculated by means of $1 \mathrm{~s}$ for correct content words and 0s for incorrect words (Porretta et al. 2016). Typos that were close to the content words were counted as 1s (e.g., yelow instead of yellow). To investigate proportions as a function of different race, English variety, and different social network diversity, we constructed a linear mixed-effects model using the lme4 package (Bates et al. 2018) in R ( $R$ version 3.6.1; R Core Team, 2019), conducted follow-up tests with lsmeans package (Lenth 2016), and corrected pairwise comparisons with the Bonferroni correction. Proportions were entered as the continuous dependent variable. As fixed effects, we included (1) Helmert-coded Variety (American English vs. British English), and (Indian English vs American + British English), (2) treatment coded Face (South Asian (a), white (b)), (3) treatment coded Diverse (LessDiverse (a), MoreDiverse(b)). Random effects were by-subject and by-item random intercepts. Random slopes were eliminated as the model did not converge. Eight participants were excluded from this analysis due to no attempt to transcribe more than $50 \%$ of the stimuli, resulting in fifty participants in the intelligibility analysis. This model explained $30 \%$ of the variance $\left(R^{2}=0.295\right)$. 
Table 2. Summary of a linear mixed effects model with proportions as the dependent variable.

\begin{tabular}{lcccc}
\hline \hline & \multicolumn{3}{c}{ proportion } \\
Fixed Effects & Estimates & std. & Error & P-Value \\
\hline Intercept & 0.91 & 0.01 & $<\mathbf{0 . 0 0 1}$ \\
Face (White) & 0.08 & 0.01 & $<\mathbf{0 . 0 0 1}$ \\
Variety (British vs American) & -0.00 & 0.01 & 0.951 \\
Variety (Indian vs American+British) & -0.04 & 0.00 & $<\mathbf{0 . 0 0 1}$ \\
Diverse (MoreDiverse) & -0.01 & 0.01 & 0.372 \\
Face (White):Variety (British vs American) & 0.00 & 0.01 & 0.661 \\
Face (White):Variety (Indian vs American+British) & 0.03 & 0.01 & $<\mathbf{0 . 0 0 1}$ \\
Face (White):Diverse(MoreDiverse) & 0.01 & 0.01 & 0.198 \\
Variety (British vs American):Diverse(MoreDiverse) & 0.00 & 0.01 & 0.911 \\
Variety (Indian vs American+British):Diverse(MoreDivers) & -0.00 & 0.00 & 0.714 \\
Face (White):Variety (British vs & -0.00 & 0.01 & 0.655 \\
American):Diverse(MoreDiverse) & & & \\
Face (White):Variety (Indian vs & -0.00 & 0.01 & 0.674 \\
American+British):Diverse(MoreDiverse) & & & \\
\hline Observations & 6120 & & \\
Marginal R / Conditional R ${ }^{2}$ & $0.116 / 0.295$ & \\
& & &
\end{tabular}

Results showed that seeing a white face versus a South Asian face impacted participants' transcription accuracy (see Table 2). Sentences paired with white faces were transcribed more accurately than those paired with South Asian faces $(b=0.075, S E=0.006, t=10.9, p<.001)$. For the variety type, Indian English was transcribed less accurately compared to American and British English $(b=-0.04, S E=0.003, t=-11.1, p<.001)$. This was further qualified by an interaction between Face (white) and Variety (Indian English vs American + British English). 
Indian English paired with white faces were transcribed more accurately compared to South Asian faces $(b=0.02, S E=0.005, t=5.2, p<.001)$. Participants' social network diversity did not have an effect on their transcription accuracy (Figure 3).

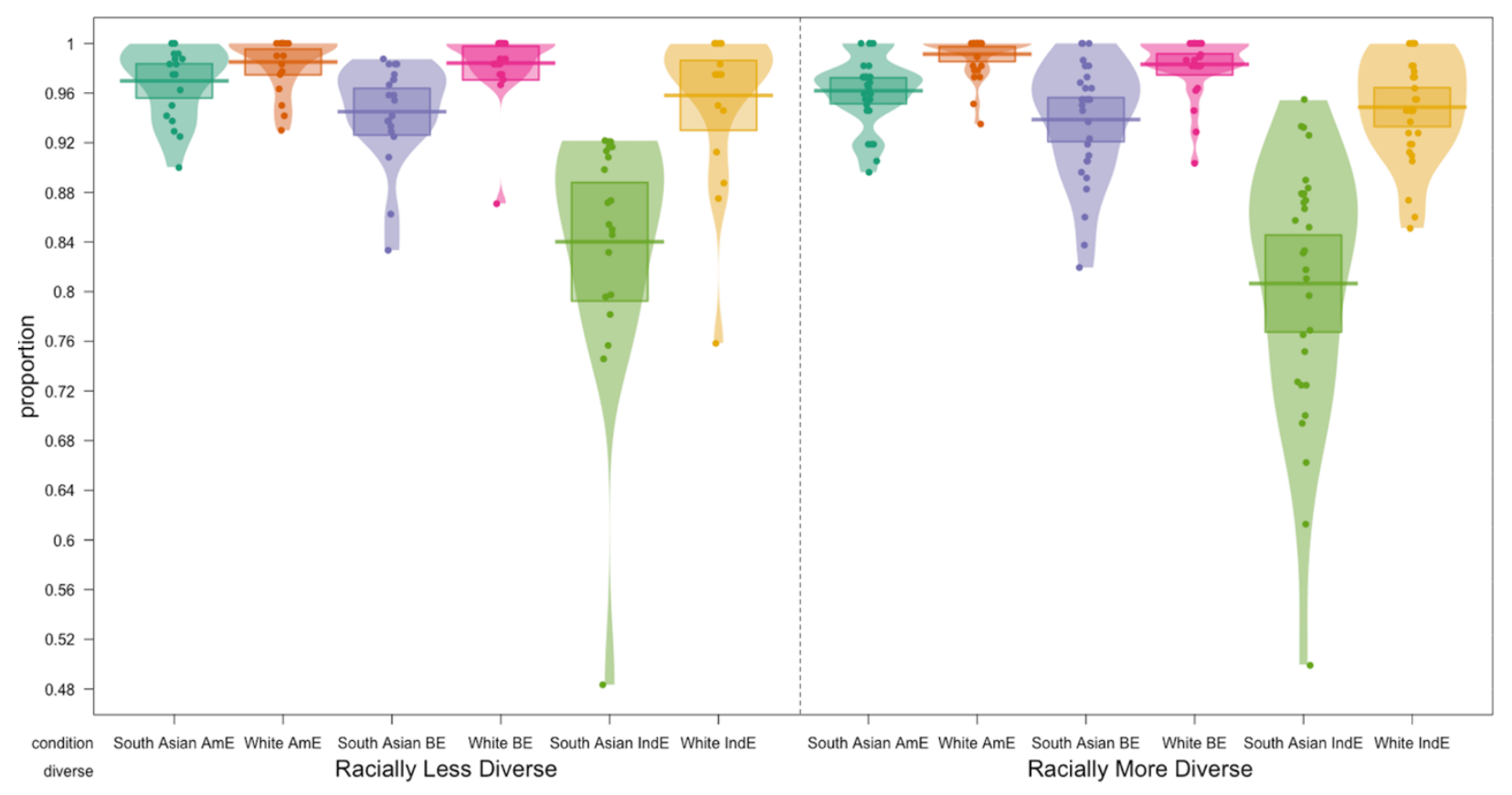

Figure 3. Proportions of correct transcription of American (AmE), British (BrE), and Indian Englush (IndE) sentences with white and South Asian faces showing both racially less and more diverse groups.

\section{Accentedness Judgments}

For the accentedness judgments task, we asked participants to judge the accentedness level of each speaker on a 9-point Likert scale. Cumulative Link Mixed Models (Christensen 2015) are proposed to account for ordinal data type which has been implemented in the ordinal package in R (Christensen 2015). This model is similar to the linear mixed effect models, but it accounts for ordinal data type by taking into consideration the likelihood that each rating could be different in size. Accent scores were the dependent variable and Variety (American, British, Indian English), Face (South Asian, white), and Diverse (LessDiverse, MoreDiverse) were added 
as the fixed effects with the same contrast coding as the intelligibility results. Random intercepts were by-subject and by-item. Random slopes were eliminated as the model did not converge. This model explained $73 \%$ of the variance $\left(R^{2}=0.73\right)$.

Table 3. Summary of a Cumulative Link Mixed Model with accentedness judgments as the dependent variable.

\begin{tabular}{|c|c|c|c|}
\hline \multirow[b]{2}{*}{ Fixed Effects } & \multicolumn{3}{|c|}{ proportion } \\
\hline & Estimates & $\begin{array}{l}\text { std. } \\
\text { Error }\end{array}$ & P-Value \\
\hline Face (White) & -1.17 & 0.10 & $<0.001$ \\
\hline Variety (British vs American) & 1.85 & 0.09 & $<0.001$ \\
\hline Variety (Indian vs American+British) & 1.16 & 0.05 & $<0.001$ \\
\hline Diverse (MoreDiverse) & -1.79 & 0.21 & $<0.001$ \\
\hline Face (White):Variety (British vs American) & 0.67 & 0.12 & $<0.001$ \\
\hline Face (White):Variety (Indian vs American+British) & 0.47 & 0.07 & $<0.001$ \\
\hline Face (White):Diverse(MoreDiverse) & 0.56 & 0.13 & $<0.001$ \\
\hline Variety (British vs American):Diverse(MoreDiverse) & -0.88 & 0.11 & $<0.001$ \\
\hline Variety (Indian vs American+British):Diverse(MoreDivers) & 0.72 & 0.06 & $<0.001$ \\
\hline $\begin{array}{l}\text { Face (White):Variety (British vs } \\
\text { American):Diverse(MoreDiverse) }\end{array}$ & -0.28 & 0.16 & 0.07 \\
\hline $\begin{array}{l}\text { Face (White):Variety (Indian vs } \\
\text { American+British):Diverse(MoreDiverse) }\end{array}$ & -0.42 & 0.09 & $<0.001$ \\
\hline Observations & 3250 & & \\
\hline Marginal $\mathrm{R}^{2}$ / Conditional $\mathrm{R}^{2}$ & $0.692 / 0$. & 738 & \\
\hline
\end{tabular}


Results showed that listeners judged sentences differently depending on whether they saw a white face or a South Asian face (see Table 3). White faces were judged to be less accented compared to South Asian faces $(b=-1.173, S E=0.105, z=-11.1, p<.001)$. There was also a main effect of the Variety type. British English was judged as more accented compared to American English $(b=1.857, S E=0.095, z=19.3, p<.001)$, and Indian English was judged as more accented compared to both American and British English combined $(b=1.161, S E=0.054$, $z=21.2, p<.001)$. Further pairwise comparisons showed that American English was judged to be more accented when paired with South Asian faces compared to white faces $(\mathrm{p}<.001)$. Participants' social network diversity impacted their accentedness judgments such that participants with more racial diversity in their social network overall judged all sentences to be less accented compared to participants with less racial diversity in their social network $(b=-$ 1.792, $S E=0.215, z=-8.3, p<.001)$ (Figure 4).

These effects were also qualified by interactions. British English paired with a white face was judged as more accented compared to American English paired with a white face $(b=0.675$, $S E=0.129, z=5.2, p<.001)$, and the same was observed for Indian English when paired with a white face; participants judged this pairing as more accented than both American and British English paired with white faces combined $(b=0.478, S E=0.07, z=6.6, p<.001)$. The three varieties also had two two-way interactions with social network diversity. British English was judged as less accented by participants with more racially diverse social networks compared to those with less racial diversity $(b=-0.884, S E=0.118, z=-7.4, p<.001)$. All these interactions were qualified by the three-way interaction for Variety by Face by Diverse $(b=-0.422, \mathrm{SE}=0.09$, $\mathrm{Z}=-4.51, p<0.001$ ), which indicates that Indian English, when paired with a white face, was 
judged as less accented by participants with more racial diversity in their social networks compared to those with less racial diversity.

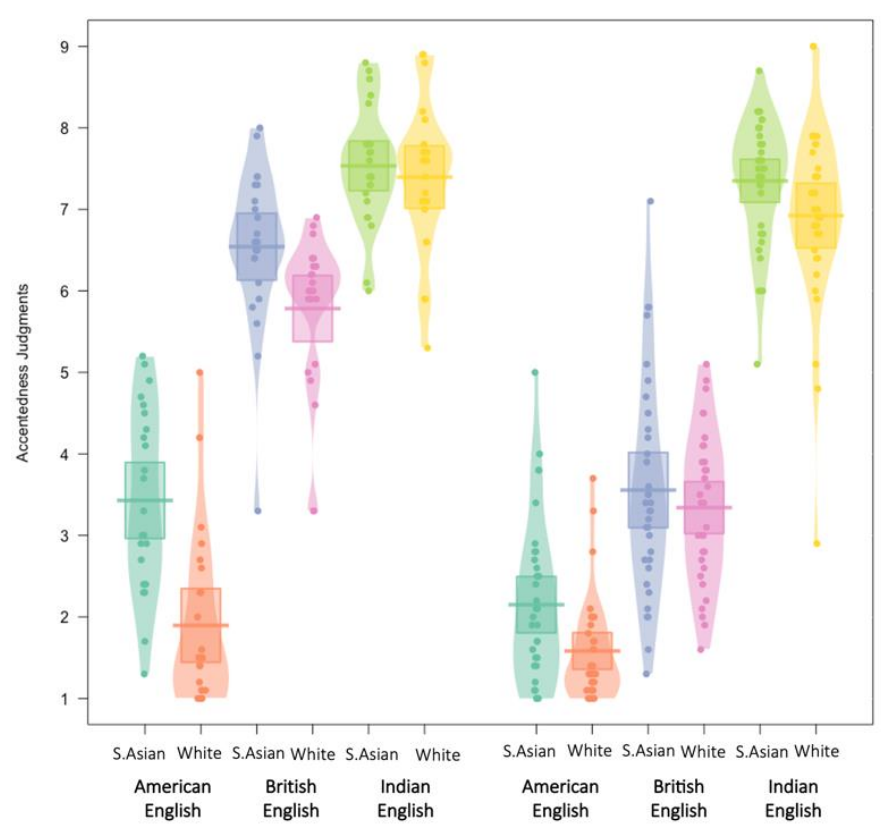

Figure 4. Accentedness Judgments of American, British, and Indian English sentences with white and South Asian faces.

\section{Discussion}

This study investigated how three varieties of English (i.e., American, British, and Indian) that belong to inner and outer circles with varying degrees of perceived prestige were evaluated when paired with a white versus a South Asian face.

The results demonstrated that in the presence of a South Asian face, all English varieties were transcribed with less accuracy than in the presence of a white face. Recall that all recordings were previously normed for their intelligibility and were all counterbalanced and Latin squared to minimize the talker effect. Therefore, the decrease in intelligibility is mediated by the face and the type of variety that participants listened to. These results align with a previous study, where Babel and Russell (2015) found a decrease in overall intelligibility when 
the presented faces switch from a white face to an East Asian face within the same language (i.e., Canadian English), demonstrating that the addition of a face image does not simply increase demand characteristics, but that presentation of non-white faces selectively hinders intelligibility. Here, we replicated their findings and expanded it to the comparison of three different varieties of English that belong to different circles with varying degree of racialization. These findings also support the fact that race does not only mediate listeners' judgments but also changes their behavior (i.e., lower intelligibility). This novel finding is crucial as it points out how racialized speakers of different English varieties can also face further stigmatization as listeners do not behave similarly when listening to their speech. It is evident that the perceived race of a speaker shapes the perception of the same linguistic tokens.

Unlike McGowan (2015), we did not find an effect of congruency as Indian English was not transcribed more accurately when paired with South Asian faces. McGowan (2015) used Chinese-accented English with three visual primes: a congruent face (i.e., a Chinese face), an incongruent face (i.e., a white face), and an uninformative silhouette. Similar to the present study, higher transcription accuracy was considered an indicator of higher intelligibility. His findings showed that seeing a congruent face (i.e., a Chinese face) helped the objective measure of intelligibility such that when participants saw a Chinese face on the screen, their expectation of Chinese-accented speech helped them transcribe more accurately. However, the differences in results could be driven from a variety of reasons. First, Chinese-English is situated in expandingcircle according to Kachru's three circle model of World Englishes (Kachru 1986). This circle hosts varieties of Englishes that are spoken by individuals who acquire English as a foreign language. It could be that expectations towards foreign language speakers of English differ from those held towards outer circle variety English speakers who grow up in multilingual spaces. 
Second, the majority of our participants live in a small college town, and although many students come to the university from across the country/world, their exposure to Indian English and South Asian individuals is still low (Kutlu \& Wiltshire 2020). A follow-up experiment could potentially measure whether participants' intelligibility judgements might change if they are exposed to Indian English or different varieties on a daily basis in more racially and linguistically diverse locales (Kutlu et al. under review) or with training (Baese-Berk et al. 2013).

Additionally, the increase in intelligibility in Indian English when paired with a white face is intriguing as it seems that when listeners saw a white face on the screen, they were more likely to transcribe the sentences accurately. It could be that participants are more fluent in processing speech pronounced by white faces. However, this fluency itself is racially constructed. The same Indian English recording becoming more intelligible only when it was produced by a white face shows that whiteness as a construct governs listeners' engagement in speech. The embodiment of whose speech is more intelligible is tied to one's race. Recall that the design of this experiment was such that the faces were shown first (before audio) so listeners made a snap judgment and then held onto their primed belief as they were listening to the sentences. Same speech recordings paired with white faces were transcribed more accurately than those paired with South Asian faces. As Soudien and Botsis (2011) argue, language remains racialized, and accents are one of the ways in which listeners' perception is mediated. Here, we showed that race leads to the assumption that the speech will be less intelligible when produced by non-white speakers.

For accentedness judgments, a similar pattern emerged such that South Asian faces increased accentedness judgments. However, in addition to this face effect, we also observed the 
effect of social networks on accentedness judgments. These findings suggest that South Asian individuals are more prone to be judged with a heavy accent compared to white individuals regardless of which variety they speak. However, these judgments are mediated by one's social network diversity such that the amount of one's perceived accentedness was lower in the more diverse social network compared to the less diverse network. However, it should be noted that British English and white faces benefited from racial diversity the most, testifying to the intricate linguistic and attitude differences among different varieties. Participants who had more racial diversity in their social networks judged British English as less accented, regardless of the face presented, compared to those in less racially diverse networks. They also judged Indian English paired with white faces as less accented compared to those in the less diverse network. As discussed earlier, language status serves a utilitarian value, meaning that a language with high status offers power in many realms (economic, individualistic, socio-economic mobility). For instance, Kircher and Fox (2019) showed that individuals who use a low status variety in their everyday life encounter prejudice and discrimination in many aspects of their lives. In the current study, for all participants, British English had a higher status compared to Indian English. While this higher status seems to be not based on race for participants with racially diverse networks, for others, it does. Overall, these novel results suggest that participants engage in speech that varies from their own variety differently depending on their racial diversity. 

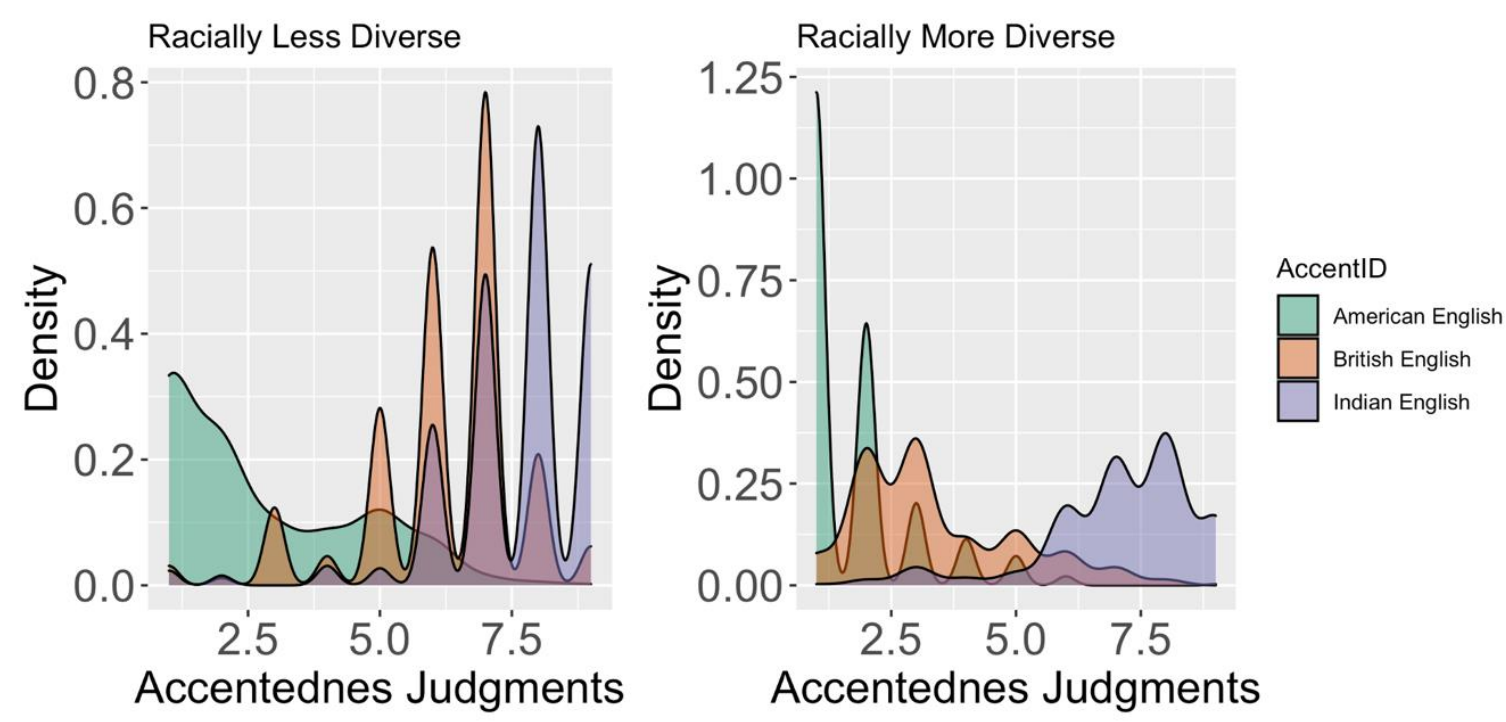

Figure 5. Density of scores for accentedness judgments for racially more and less diverse groups for American, British, and Indian English collapsed over faces. X-axis represents the accentedness judgments scale (1-9, 9=heavily accented).

Bucholtz and Hall (2016: 178) argue that voice as it emerges from the body indexes and auditorily locates the positionality of the body in a given social space which is then interpreted by listeners in relation to one's gender, sexuality, and race (Oostendorp 2021). For many years, both in everyday interactions and in linguistic research, inner circle varieties (i.e., American, British English) have been reflected as the embodiment of native speakerism. These varieties fill the social spaces with uncontested ideologies leaving outer circle varieties and their speakers out of the picture. Here, we showed that these ideologies are evident in both racially more and less diverse networks in different form, and they shape how listeners engage in speech produced by white and non-white individuals.

This paper introduced not only a comparison of three different English varieties but how they are perceived depending on the racial background of the face associated with those English varieties. Here, we went beyond speaker-dependent factors and further investigated listeners' 
background through an extensive language history background questionnaire as well as a social network questionnaire. Recently, it has been shown that social networks can identify linguistic preferences in multilingual places (Tiv et al. 2020). We argue that social network questionnaire is an important tool moving forward in understanding how language dynamics are shaped and how speaker-listener relationships emerge in varying networks. In the context of geopolitical spaces where multilingual practices are often endangered by nationalist ideologies, discrimination, or linguistic stigmatization (Kutlu \& Kircher 2021), social network approach brings multitude of opportunities to understand language dynamics in multilingual spaces. Listeners' experience with language and society builds their linguistic representations (Babel \& Mellesmoen 2019). Therefore, social network analysis can move us further in terms of understanding language and social dynamics regarding how listeners' linguistic representations are shaped. Particularly, this approach should be carried to classroom environments to assess students' engagement with other peers along with their engagement with individuals who are outside of their classrooms. As Ortega (2021) argues critical education is essential to challenge inequality and power asymmetries observed in academic and non-academic settings. It is the case that social network analysis can guide understanding power dynamics in different language communities. What is more pressing is the representations needed both in classrooms and in higher education for different English varieties which will then shift the dynamics of different networks.

All these findings have important implications for classroom practices, language policy making, language assessment tools, and multilingual practices. That listeners' behavior in engaging in understanding speech and their accentedness judgments change depending on the race of the face they saw on the computer screen is directly related to what type of teachers are 
expected to teach English worldwide or what standard English should look like in classrooms. When combined with institutionalized racism, these findings are alarming. Consequently, it impacts the assessment of speakers of different English varieties. For instance, Australian English speakers are not asked to prove English proficiency whereas Indian English speakers do need to provide English proficiency in North American schooling systems. How these varieties need to be assessed is an important question. As it can be seen from the results of this study, intelligibility is not the key to assessing accentedness. In fact, both intelligibility and accentedness are associated with and tied to racialized concepts such as whiteness. From the speaker perspective, these results are also important for other minoritized groups. For instance, Black students have the lowest participation in language learning classes in the US (Anya 2020). It is not that these students do not have interests in multilingualism, but that their language use is systematically criticized or racialized (Flores \& Rosa 2015; Subtirelu 2015). There needs to be more interdisciplinary research on speech perception and how racialized bodies who are multilinguals or who would like to practice multilingualism should do so without their language practices being punished or critically disapproved. In this paper, we expanded current speech perception literature to a more inclusive one (see Subtirelu \& Lindemann 2014 for various strategies).

Finally, it is evident that the ideal native speakerism ideologies need to be further reevaluated as their pursuit is leading towards more racial disparities in language research, teaching, and policy making (Cheng et al. 2021; Tiv et al. 2021). Therefore, more critical postcolonialism and critical race ${ }^{8}$ theories are needed in language research. One phenomenon that has expanded our views on classroom dynamics has been that of translanguage practices in

\footnotetext{
${ }^{8}$ As well as critical gender theories, which are out of the scope of this study.
} 
the classroom. These practices are not bound to language labels but acknowledge the fluidity of language and its users (e.g., Wei 2018). These practices are better suited for eliminating ideal native speakerism ideologies in educational practices. It is non-trivial to acknowledge that everybody has an accent. Our research thus needs to reflect how our educational systems are governed by these prejudice ideologies.

\section{Declaration of interest statement}

The authors declare that there is no conflict of interest ${ }^{9}$.

Acknowledgement: We would like to thank the editors of Applied Linguistics and all reviewers who helped us tremendously in preparing this manuscript. The authors also would like to thank Sabrina Fiske and Holly Redman for their help with data collection, Dr. Jason Rothman and Dr. Lisa Scott for their help with stimuli preparation.

\section{References}

Anya, U. (2020). 'African Americans in World Language Study: The Forged Path and Future Directions', Annual Review of Applied Linguistics, 40: 97-112. DOI: 10.1017/S0267190520000070

Anya, U., Avineri, N., Carris, L. M., \& Valencia, V. (2010). 'Languages, Identities, and Accents: Perspectives from the 2010 Linguistic Diversity Conference', 14.

Babel, M., \& Mellesmoen, G. (2019). 'Perceptual adaptation to stereotyped accents in audiovisual speech', In Proceedings of the 19th International Congress of Phonetic Sciences, Melbourne, Australia (pp. 1044-1048).

Babel, M., \& Russell, J. (2015). 'Expectations and speech intelligibility', The Journal of the Acoustical Society of America, 137/5: 2823-33. DOI: 10.1121/1.4919317

Baese-Berk, M. M., Bradlow, A. R., \& Wright, B. A. (2013). 'Accent-independent adaptation to foreign accented speech', J. Acoust. Soc. Am., 8.

Bates, D., Kliegl, R., Vasishth, S., \& Baayen, H. (2018). 'Parsimonious Mixed Models', arXiv:1506.04967 [stat].

Bradlow, A. R., \& Alexander, J. A. (2007). 'Semantic and phonetic enhancements for speech-innoise recognition by native and non-native listeners', The Journal of the Acoustical Society of America, 121/4: 2339-49. DOI: 10.1121/1.2642103

\footnotetext{
${ }^{9}$ Mehrgol Tiv (PhD, McGill University) is currently a postdoctoral researcher at the U.S.

Census Bureau, where she conducts research on the social-cognitive processes underlying race, language, and identity. Any views expressed in this paper are hers and do not necessarily reflect the views of the U.S. Census Bureau.
} 
Campbell-Kibler, K. (2011). 'Intersecting variables and perceived sexual orientation in men.', American Speech, 86/1: 52-68.

Cheng, L. S. P., Burgess, D., Vernooij, N., Solís-Barroso, C., \& Namboodiripad, S. (n.d.). 'The problematic concept of "native speaker" in Psycholinguistics: Replacing vague and harmful terminology with inclusive and accurate measures', 39.

Christensen, R. H. B. (2015). 'Analysis of ordinal data with cumulative link models estimation with the R-package ordinal', 31.

Cowie, C. (2007). 'The accents of outsourcing: the meanings of "neutral" in the Indian call centre industry', World Englishes, 26/3: 316-30. DOI: 10.1111/j.1467971X.2007.00511.X

Derwing, T. (2003). 'What do ESL students say about their accents?', Canadian Modern Language Review, 59/4: 547-67.

Derwing, T. M., \& Munro, M. J. (1997). 'Accent, intelligibility, and comprehensibility: Evidence from FourL1s', Studies in Second Language Acquisition, 19/1: 1-16. DOI: $10.1017 / \mathrm{S} 0272263197001010$

Dewaele, J.-M. (2017). 'Why the Dichotomy "L1 Versus LX User" is Better than 'Native Versus Non-native Speaker', Applied Linguistics, amw055. DOI: 10.1093/applin/amw055

Dewaele, J.-M., Mercer, S., Talbot, K., \& von Blanckenburg, M. (2020). 'Are EFL pre-service teachers' judgment of teaching competence swayed by the belief that the EFL teacher is a L1 or LX user of English?', European Journal of Applied Linguistics.

Dragojevic, M. (2020). 'Extending the fluency principle: Factors that increase listeners' processing fluency positively bias their language attitudes', Communication Monographs, 87/2: 158-78. DOI: 10.1080/03637751.2019.1663543

Dragojevic, M., Berglund, C., \& Blauvelt, T. K. (2018). 'Figuring Out Who's Who: The Role of Social Categorization in the Language Attitudes Process', Journal of Language and Social Psychology, 37/1: 28-50. DOI: 10.1177/0261927X17706942

Floccia, C., Goslin, J., Girard, F., \& Konopczynski, G. (2006). 'Does a regional accent perturb speech processing?', Journal of Experimental Psychology: Human Perception and Performance, 32/5: 1276-93. DOI: 10.1037/0096-1523.32.5.1276

Flores, N., \& Rosa, J. (2015). 'Undoing Appropriateness: Raciolinguistic Ideologies and Language Diversity in Education', Harvard Educational Review, 85/2: 149-71. DOI: 10.17763/0017-8055.85.2.149

Garrett, P. (2010). Attitudes to language. Cambridge: Cambridge University Press.

Giles, H., \& Watson, B., M. (2013). The social meanings of language, dialect and accent: international perspectives on speech styles. New York, NY, United States: Peter Lang Publishing.

Higgins, C. (2003). "“Ownership" of English in the Outer Circle: An Alternative to the NS-NNS Dichotomy', TESOL Quarterly, 37/4: 615. DOI: 10.2307/3588215

Hill, J. (2008). The Everyday Language of White Racism. Massachusetts: Wiley-Blackwell Publishing.

Holliday, A. (2006). 'Native-speakerism', ELT Journal, 60/4: 385-7. DOI: 10.1093/elt/cc1030

Holliday, Adrian, \& Aboshiha, P. (2009). 'The Denial of Ideology in Perceptions of "Nonnative Speake” Teachers', TESOL Quarterly, 43/4: 669-89. DOI: 10.1002/j.15457249.2009.tb00191.x

Kachru, B. B. (1986). The alchemy of English: The spread, functions, and models of non-native Englishes. Urbana and Chicago: University of Illinois Press. 
Kang, O., \& Rubin, D. L. (2009). 'Reverse Linguistic Stereotyping: Measuring the Effect of Listener Expectations on Speech Evaluation', Journal of Language and Social Psychology, 28/4: 441-56. DOI: 10.1177/0261927X09341950

Kircher, R. (2016). 'The Matched-Guise Technique'. Research Methods in Intercultural Communication.

Kircher, R., \& Fox, S. (2019). 'Multicultural London English and its speakers: a corpusinformed discourse study of standard language ideology and social stereotypes', Journal of Multilingual and Multicultural Development, 1-19. DOI: 10.1080/01434632.2019.1666856

Kubota, R. (2020). 'Confronting Epistemological Racism, Decolonizing Scholarly Knowledge: Race and Gender in Applied Linguistics', Applied Linguistics, 41/5: 712-32. DOI: 10.1093/applin/amz033

Kutlu, E. (2020). 'Now You See Me, Now You Mishear Me: Raciolinguistic accounts of speech perception in different English varieties', Journal of Multilingual and Multicultural Development, 1-15. DOI: 10.1080/01434632.2020.1835929

Kutlu, E., \& Kircher, R. (2021). 'A Corpus-Assisted Discourse Study of Attitudes toward Spanish as a Heritage Language in Florida', Languages, 6/1: 38. DOI: 10.3390/languages6010038

Kutlu, E., \& Wiltshire, C. (2020). 'Where do negative stereotypes come from? The case of Indian English in the USA', Proceedings of the Linguistic Society of America, 5/1: 74. DOI: $10.3765 /$ plsa.v5i1.4669

Kutlu, E., Tiv, M., Wulff, S., \& Titone, D. (under review). Does Race Impact Speech Perception? An Account of Accented Speech in Two Different Multilingual Locales.

Lambert, W. E., Hodgson, R. C., Gardner, R. C., \& Fillenbaum, S. (1960). 'Evaluational reactions to spoken languages.', The Journal of Abnormal and Social Psychology, 60/1: 44-51. DOI: 10.1037/h0044430

Lemhöfer, K., \& Broersma, M. (2012). 'Introducing LexTALE: A quick and valid Lexical Test for Advanced Learners of English', Behavior Research Methods, 44/2: 325-43. DOI: 10.3758/s13428-011-0146-0

Lenth, R. V. (2016). 'Least-Squares Means: The $R$ Package Ismeans', Journal of Statistical Software, 69/1. DOI: 10.18637/jss.v069.i01

Lev-Ari, S. (2016). 'How the Size of Our Social Network Influences Our Semantic Skills', Cognitive Science, 40/8: 2050-64. DOI: 10.1111/cogs.12317

_. (2017). 'Talking to fewer people leads to having more malleable linguistic representations', (K. Smith, Ed.)PLOS ONE, 12/8: e0183593. DOI:

10.1371/journal.pone.0183593

_ (2018). 'Social network size can influence linguistic malleability and the propagation of linguistic change', Cognition, 176: 31-9. DOI: 10.1016/j.cognition.2018.03.003

Lev-Ari, S., \& Shao, Z. (2017). 'How social network heterogeneity facilitates lexical access and lexical prediction’, Memory \& Cognition, 45/3: 528-38. DOI: 10.3758/s13421-016-0675$\mathrm{y}$

Li, P., Zhang, F., Yu, A., \& Zhao, X. (2020). 'Language History Questionnaire (LHQ3): An enhanced tool for assessing multilingual experience', Bilingualism: Language and Cognition, 23/5: 938-44. DOI: 10.1017/S1366728918001153

Lippi-Green, R. (1994). 'Accent, standard language ideology, and discriminatory pretext in the courts', Language in Society, 23/2: 163-98. DOI: 10.1017/S0047404500017826 
Ma, D. S., Correll, J., \& Wittenbrink, B. (2015). 'The Chicago face database: A free stimulus set of faces and norming data', Behavior Research Methods, 47/4: 1122-35. DOI:

$10.3758 / \mathrm{s} 13428-014-0532-5$

Mahboob, A. (2018). 'Beyond Global Englishes: Teaching English as a Dynamic Language', RELC Journal, 49/1: 36-57. DOI: 10.1177/0033688218754944

Mahboob, A., \& Golden, R. (2013). 'VOICES IN ASIA JOURNAL', 1/1: 10.

Makoe, P., \& McKinney, C. (2014). 'Linguistic ideologies in multilingual South African suburban schools', Journal of Multilingual and Multicultural Development, 35/7: 65873. DOI: $10.1080 / 01434632.2014 .908889$

Maxwell, O., Diskin-Holdaway, C., \& Loakes, D. (2021). 'Attitudes towards Indian English among young urban professionals in Hyderabad, India', World Englishes, weng. 12550. DOI: $10.1111 /$ weng. 12550

McGowan, K. B. (2015). 'Social Expectation Improves Speech Perception in Noise', Language and Speech, 58/4: 502-21. DOI: 10.1177/0023830914565191

Milroy, J. (n.d.). 'The ideology of the standard'. The Routhledge companion to sociolinguistics.

Munro, M. J., \& Derwing, T. M. (1995). 'Processing Time, Accent, and Comprehensibility in the Perception of Native and Foreign-Accented Speech', Language and Speech, 38/3: 289306. DOI: $10.1177 / 002383099503800305$

Niedzielski, N. (1999). 'The Effect of Social Information on the Perception of Sociolinguistic Variables', Journal of Language and Social Psychology, 18/1: 62-85. DOI: 10.1177/0261927X99018001005

Oostendorp, M. (2021). 'Raced Repertoires: The Linguistic Repertoire as Multi-Semiotic and Racialized', Applied Linguistics, amab018. DOI: 10.1093/applin/amab018

Ortega, Y. (2021). "II wanted to be white": understanding power asymmetries of whiteness and racialisation', Whiteness and Education, 1-16. DOI: 10.1080/23793406.2021.1920046

Paladino, M. P., \& Mazzurega, M. (2019). 'One of Us: On the Role of Accent and Race in RealTime In-Group Categorization', Journal of Language and Social Psychology, 0261927X1988409. DOI: 10.1177/0261927X19884090

Porretta, V. (2016). 'The influence of gradient foreign accentedness and listener experience on word recognition', Journal of Phonetics, 21.

Ramjattan, V.A. (2019). 'Raciolinguistics and the aesthetic labourer', Journal of Industrial Relations, 61/5: 726-38. DOI: 10.1177/0022185618792990

Rosa, J. (2019). Looking like a language, sounding like a race: Raciolinguistic ideologies and the learning of Latinidad. Oxford University Press.

Rosa, J. D. (2016). 'Standardization, Racialization, Languagelessness: Raciolinguistic Ideologies across Communicative Contexts', Journal of Linguistic Anthropology, 26/2: 162-83. DOI: $10.1111 /$ jola.12116

Rubin, D. L. (1992). 'Nonlanguage factors affecting undergraduates' judgments of nonnative English-speaking teaching assistants', Research in Higher Education, 33/4: 511-31. DOI: 10.1007/BF00973770

Satone, M. (2017). “"KKWETC” Indian Face Database', International Journal of Engineering Trends and Technology, 54/1: 4.

Sekimoto. (2018). 'Race and the Senses: Toward Articulating the Sensory Apparatus of Race', Critical Philosophy of Race, 6/1: 82. DOI: 10.5325/critphilrace.6.1.0082

Shuck, G. (2006). 'Racializing the Nonnative English Speaker', Journal of Language, Identity \& Education, 5/4: 259-76. DOI: 10.1207/s15327701jlie0504_1 
Soudien, C., \& Botsis, H. (2011). 'Accent on Desire: Desire and Race in the Production of Ideological Subjectivities in Post-Apartheid South Africa', Feminist Formations, 23/3: 89-109. DOI: 10.1353/ff.2011.0039

Subtirelu, N. C., \& Lindemann, S. (2014). 'Teaching First Language Speakers to Communicate Across Linguistic Difference: Addressing Attitudes, Comprehension, and Strategies', Applied Linguistics, amu068. DOI: 10.1093/applin/amu068

Subtirelu, N. C. (2015). "She does have an accent but...": Race and language ideology in students' evaluations of mathematics instructors on RateMyProfessors.com', Language in Society, 44/1: 35-62. DOI: 10.1017/S0047404514000736

Subtirelu, N. C., Borowczyk, M., Thorson Hernández, R., \& Venezia, F. (2019). 'Recognizing Whose Bilingualism? A Critical Policy Analysis of the Seal of Biliteracy', The Modern Language Journal, 103/2: 371-90. DOI: 10.1111/modl.12556

Tiv, M., Gullifer, J., Feng, R. Y., \& Titone, D. (2020). Using Network Science to Map What Montréal Bilinguals Talk about Across Languages and Communicative Contexts. Journal of Neurolinguistics, 56. https://doi.org/10.1016/j.jneuroling.2020.100913

Tiv, M., Kutlu, E., Gullifer, J. W., Feng, R. Y., Doucerain, M., \& Titone, D. (under review). Bridging personal and ecological language dynamics: A systems framework of bilingualism.

Van Engen, K. J., \& Bradlow, A. R. (2007). 'Sentence recognition in native- and foreignlanguage multi-talker background noise', The Journal of the Acoustical Society of America, 121/1: 519-26. DOI: 10.1121/1.2400666

Van Engen, K. J., Phelps, J. E. B., Smiljanic, R., \& Chandrasekaran, B. (2014). 'Enhancing Speech Intelligibility: Interactions Among Context, Modality, Speech Style, and Masker', Journal of Speech, Language, and Hearing Research, 57/5: 1908-18. DOI: 10.1044/JSLHR-H-13-0076

Wei, L. (2018). 'Translanguaging as a Practical Theory of Language', Applied Linguistics, 39/1: 9-30. DOI: 10.1093/applin/amx039

Xie, X., Theodore, R. M., \& Myers, E. B. (2017). 'More than a boundary shift: Perceptual adaptation to foreign-accented speech reshapes the internal structure of phonetic categories.', Journal of Experimental Psychology: Human Perception and Performance, 43/1: 206-17. DOI: 10.1037/xhp0000285

Yi, H.-G., Phelps, J. E. B., Smiljanic, R., \& Chandrasekaran, B. (2013). 'Reduced efficiency of audiovisual integration for nonnative speech', The Journal of the Acoustical Society of America, 134/5: EL387-93. DOI: 10.1121/1.4822320

Yi, H.-G., Smiljanic, R., \& Chandrasekaran, B. (2014). 'The neural processing of foreignaccented speech and its relationship to listener bias', Frontiers in Human Neuroscience, 8. DOI: 10.3389/fnhum.2014.00768

Zheng, Y., \& Samuel, A. (2017). 'Does seeing an Asian face make speech sound more accented?', 19. 
Appendix A
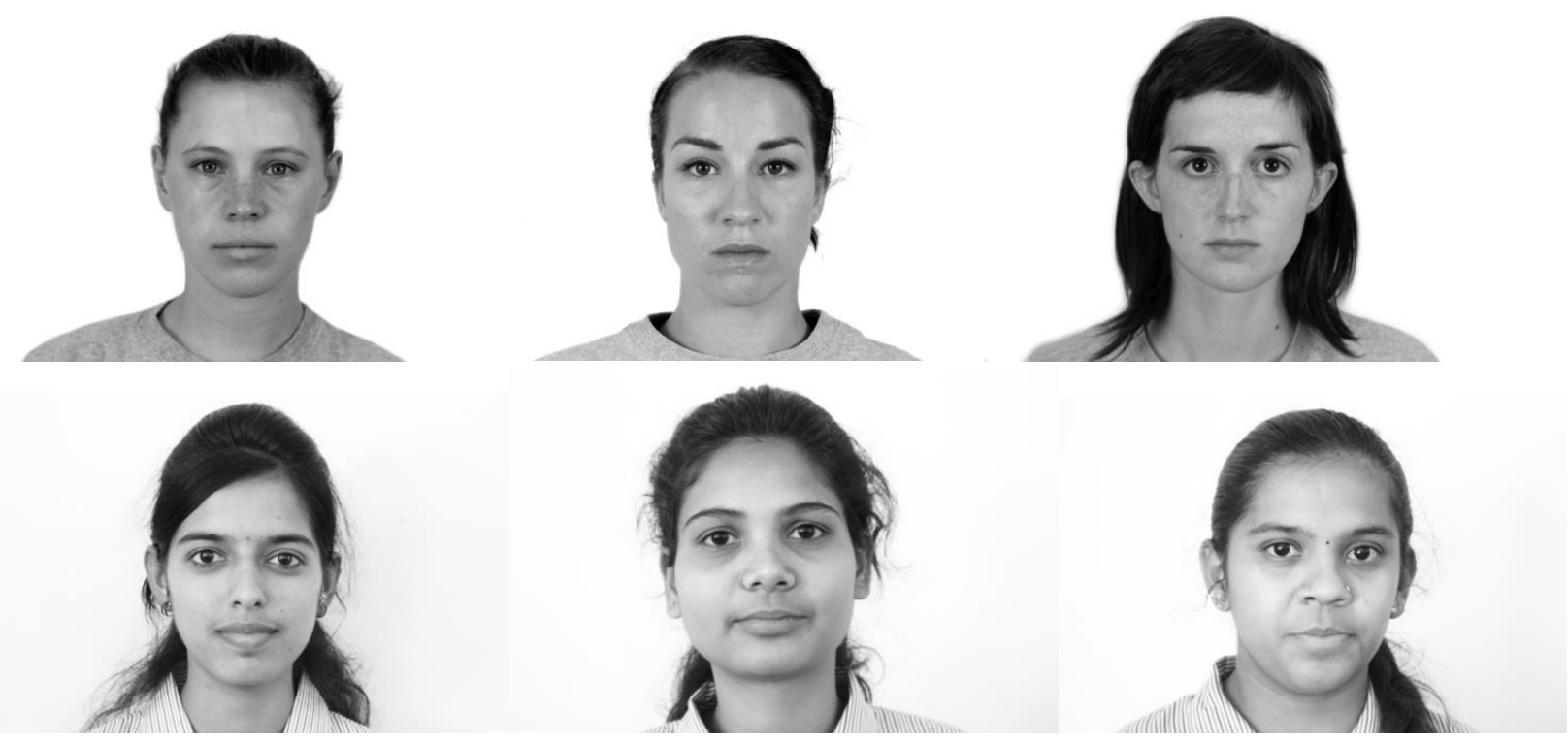